\title{
THỰC TRẠNG CÔNG TÁC CHỦ NHIẸM LỚP Ở CÁC TRƯỜNG TRUNG HỌC CƠ SỞ TRÊN ĐỊA BÀN THỊ XÃ THUẬN AN, TỈNH BÌNH DƯƠNG
}

\author{
PHAN THỊ TỐ OANH ${ }^{1}$, TRÀ̀N THỤY HƯNG HẢO ${ }^{2}$ \\ ${ }^{1}$ Trường Đại học Công nghiệp Thành phố Hồ Chí Minh, \\ ${ }^{2}$ Trường THCS Bình Chuẩn, Bình Dưong; \\ phanthitooanh@iuh.edu.vn
}

Tóm tắt. Công tác chủ nhiệm lớp là một trong những nhiệm vụ trọng tâm của nhà trường phổ thông nói chung và THCS nói riêng. Bài viết đề cập đến thực trạng công tác chủ nhiệm lớp của GVCN ở các trường THCS trên địa bàn thị xã Thuận An, tỉnh Bình Dương (nhận thức, vai trò và thực hiện nội dung công tác chủ nhiệm). Từ đó, đề xuất một số kiến nghị nhằm tăng cường hiệu quả của công tác chủ nhiệm lớp nhằm góp phần nâng cao chất lượng GD toàn diện, đáp ứng các yêu cầu đổi mới căn bản, toàn diện GD-ĐT và mục tiêu phát triển kinh tế - xã hội của địa phương.

Từ khóa. Giáo viên chủ nhiệm, công tác chủ nhiệm lớp, trung học cơ sở.

\section{THE STATUS OF GRADUATE WORKERS AT THE JUNIOR HIGH SCHOOL IN THE THUAN AN TOWNSHIP, BINH DUONG PROVINCE}

\begin{abstract}
The managerial responsibility of form teachers is one of the important issues of senior high schools in general and junior high schools in particular. The article indicates the actual status of the managerial responsibility of form teachers in junior high schools in Thuan An town, Binh Duong province (awareness, role and implementation of the managerial responsibility). On the basis of the findings, the author offers some methods to enhance the effectiveness for the managerial responsibility of form teachers, which will contribute to comprehensively improve the quality of education, fully satisfy the fundamental reform needs, the completeness in education and training as well as the objectives for economic and social development of the local authority.
\end{abstract}

Key words. form teacher, assignments of homeroom teacher, junior high school.

\section{1 ĐặT VẤN Đề}

Công tác chủ nhiệm lớp là công tác tổ chức, quản lý một lớp học sao cho khi GV có hoặc không có trong lớp học thì mọi hoạt động trong lớp vẫn duy trì ổn định, có tính tự giác cao và mọi việc vẫn hoàn thành tốt. Sự phát triển nhận thức và khả năng tiếp thu của người HS chỉ thực sự hiệu quả khi tập thể lớp là một tập thể vững mạnh và lớp học phải là ngôi nhà thứ hai của mỗi HS. Để đạt được điều đó thì GVCNL phải có phương pháp chủ nhiệm tốt và hiệu quả. Công tác chủ nhiệm của một $G V$ thành công là đồng nghĩa với việc giúp các em hoàn thiện mình hơn và xây dựng một tập thể lớp giúp cho các thành viên trong đó ngày càng tiến bộ. CTCNL là hoạt động tổ chức, quản lý và xây dựng một tập thể lớp vững mạnh và tạo điều kiện để tiến hành các hoạt động dạy học và GD. Tìm hiểu và đánh giá thực trạng công tác chủ nhiệm lớp ở một số trường THCS trên địa bàn Thị xã Thuận An tỉnh Bình Dương về nhận thức, về thực hiện nội dung công tác chủ nhiệm lớp theo Thông tư 12/2011/TT-BGDĐT là nội dung chính được đề cập trong bài báo này.

\section{PHƯƠNG PHÁP NGHIÊN CÚU}

Nghiên cứu chủ yếu được thực hiện bằng phương pháp điều tra và phỏng vấn sâu cùng phương pháp quan sát để bổ sung thông tin trong quá trình phân tích kết quả nghiên cứu. Các câu hỏi thang đo theo 4 mức độ, điểm số từ $1 \rightarrow 4$ (Không thực hiện - Thỉnh thoảng - Thường xuyên - Rất thường xuyên) và (Không quan tâm/ Không quan trọng/Chưa đạt/Không thích- Ít quan tâm/Ít quan trọng/Khá/Ít thích Quan tâm/ Quan trọng/ Tốt/Thích - Rất quan tâm/Rất quan trọng/ Rất tốt/ Rất thích ) để xác định sự đánh 
giá các ý kiến được khảo sát có sự khác biệt như thế nào? Khách thể tham gia khảo sát gồm $200 \mathrm{CBQL}$ GV và GVCN lớp (trong đó có $15 \mathrm{CBQL}$ ); $500 \mathrm{HS}$ của 5 trường (THCS Bình Chuẩn, THCS Nguyễn Thái Bình, THCS Trần Đại Nghĩa, THCS Trịnh Hoài Đức, THCS Phú Long) trên địa bàn Thị xã Thuận An, tỉnh Bình Dương năm học 2016 -2017.

\section{KẾT QUẢ NGHIÊN CÚ̉ U}

\subsection{Về nhận thức của $\mathrm{CBQL}$ và GVCNL đối với $\mathrm{CTCNL}$}

CTCN là một hoạt động quan trọng trong việc nâng cao chất lượng GD toàn diện, chính vì lẽ đó hoạt động của người GVCN lớp rất cần sự quan tâm, định hướng từ phía lãnh đạo, giúp cho GVCN xác định đúng mục tiêu của GD. Để tìm hiểu mức độ quan tâm của lãnh đạo đối với $\mathrm{CTCN}$ trên địa bàn Thị xã Thuận An, chúng tôi tiến hành khảo sát $200 \mathrm{CBQL}$ và $\mathrm{GV}$ của 5 trường trong địa bàn kết quả như sau:

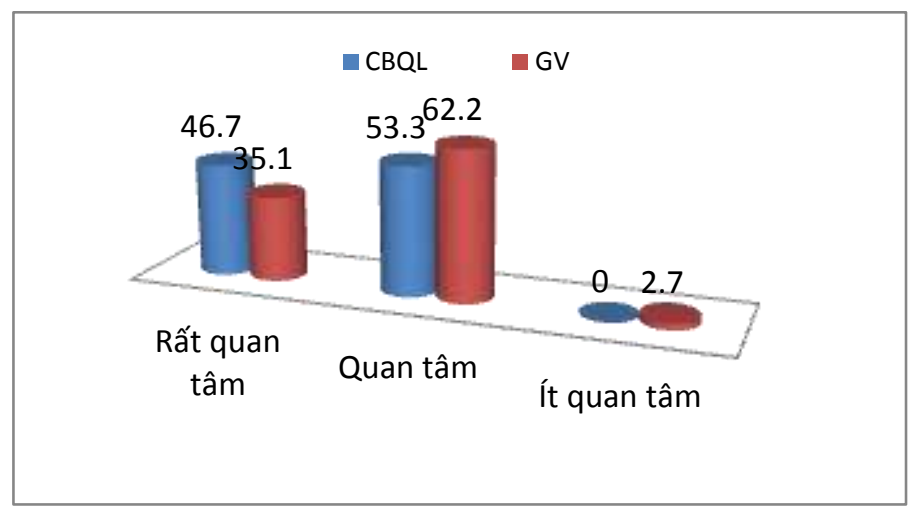

Biểu đồ 1 . Sự quan tâm của lãnh đạo về CTCN

Biểu đồ 1 cho thấy: $46.7 \%$ ý kiến $\mathrm{CBQL}$ đánh giá rất quan tâm, $35.1 \%$ ý kiến $\mathrm{GV}$ đánh giá rất quan tâm, $53.3 \%$ ý kiến $\mathrm{CBQL}$ đánh giá quan tâm, $62,2 \%$ ý kiến $\mathrm{GV}$ đánh giá quan tâm của lãnh đạo đến công tác chủ nhiệm, đây là một tín hiệu tích cực. Điều này chứng tỏ, lãnh đạo phòng giáo dục rất quan tâm đến công tác chủ nhiệm tại các trường THCS. Kết quả thống kê cho thấy vẫn còn $2.7 \%$ ý kiến GV đánh giá lãnh đạo phòng giáo dục ít quan tâm đến công tác chủ nhiệm. Phỏng vấn GV V - Trường THCS THĐ cho rằng: "Làm công tác chủ nhiệm vất vả nhung chăng có chế độ gì ngoài 4 tiết kiêm nhiệm" hay "Hướng dẫn về công tác chủ nhiệm không có một văn bản nào cư thể, có chăng nữa chỉ là nói chung chung" (GVCN A trường THCS BC). Như vậy, bên cạnh các văn bản chỉ đạo, hướng dẫn về công tác chủ nhiệm, chế độ đãi ngộ giáo viên chủ nhiệm vẫn còn hạn chế. Đây cũng là một vấn đề cần lưu tâm giải quyết.

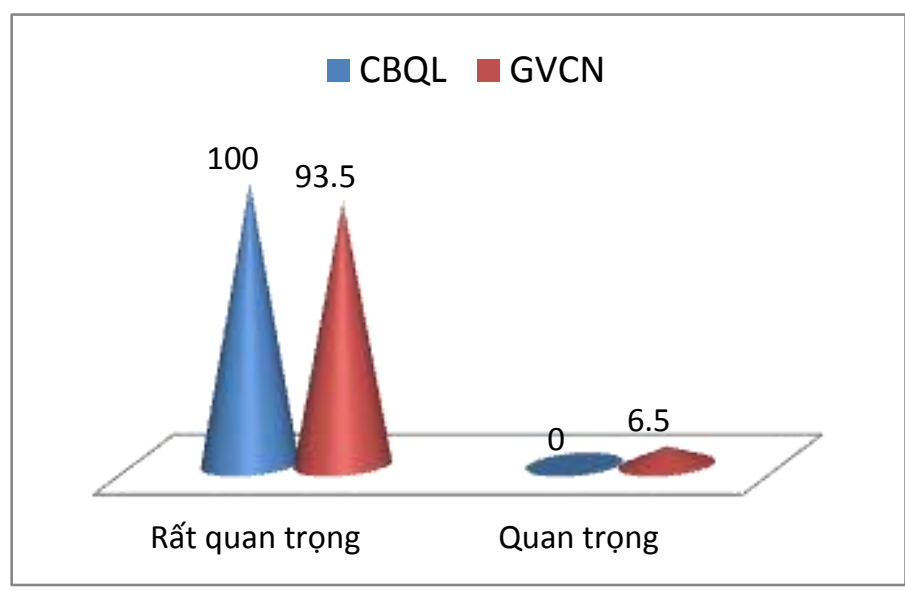

Biểu đồ 2. Nhận thức của $\mathrm{CBQL}$ và $\mathrm{GVCN}$ về vai trò $\mathrm{CTCN}$ 
Kết quả khảo sát ở biểu đồ 2 cho thấy $\mathrm{CBQL}$ và GVCN nhận thức đúng và đánh giá cao vai trò của GVCN trong công tác quản lý giáo dục học sinh. Có $100 \%$ GBQL đánh giá vai trò GVCN rất quan trọng, có $93.5 \% \mathrm{GVCN}$ đánh giá vai trò của $\mathrm{GVCN}$ rất quan trọng và $6 \% \mathrm{GVCN}$ đánh giá quan trọng trong công tác quản lý và giáo dục $\mathrm{HS}$. Điều này chứng tỏ $\mathrm{CBQL}$ và $\mathrm{GV}$ nhận thức rất đúng vai trò của $\mathrm{GVCN}$ trong công tác giáo dục HS. Đây là một yếu tố tích cực của ngành GD Thị xã Thuận $\mathrm{An}$ cần duy trì và phát huy.

\subsection{Về thực hiện nội dung công tác chủ nhiệm}

GVCNL có vị trí rất quan trọng trong việc hình thành và phát triển đạo đức, trí tuệ, thể chất, thẩm mĩ và các kỹ năng cơ bản của $\mathrm{HS}$, là cầu nối giữa gia đình, nhà trường và xã hội. Kết quả khảo sát sự quan tâm của GVCNL như sau:

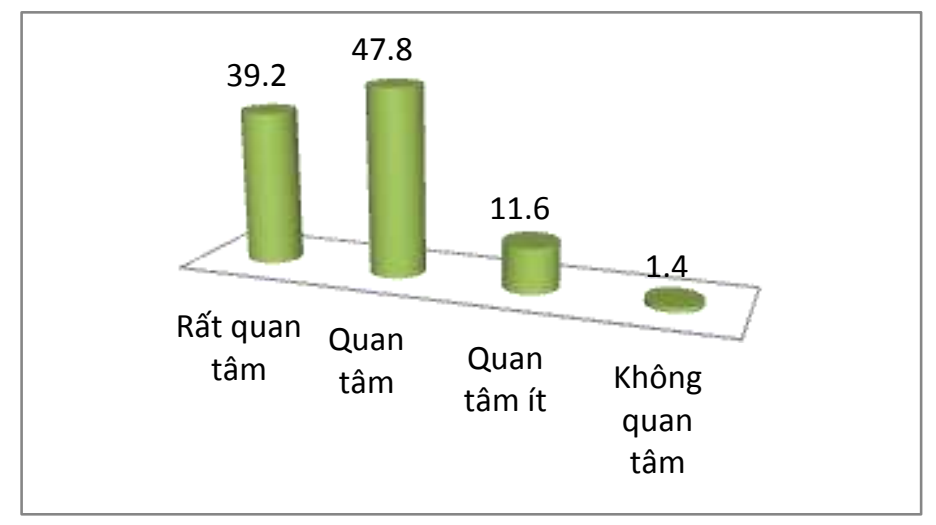

Biểu đồ 3. Mức độ quan tâm của GV đến HS lớp chủ nhiệm

Biểu đồ 3 cho thấy mức độ quan tâm đến HS lớp chủ nhiệm khá cao, có $87 \%$ ý kiến đánh giá GVCN quan tâm và rất quan tâm đến HS lớp chủ nhiệm. Có thể nhận xét, đội ngũ $\mathrm{GV}$ làm $\mathrm{CTCN}$ rất có ý thức trong công tác giáo dục HS. Bên cạnh đó vẫn còn $11.6 \%$ ý kiến đánh giá quan tâm ít và $1.4 \%$ ý kiến đánh giá không quan tâm, đây là một tỉ lệ không nhỏ. Qua trò chuyện cùng HS A trường THCS NTB "Một tuần em chỉ gặp cô chủ nhiệm có 2 lần (1 lần giờ dạy và một lần giờ chủ nhiệm)" hay phụ huynh HS L trường THCS PL "Vùa rồi con tôi mất máy tính trên lớp, tôi búc xúc gọi điện cho GVCN nhưng mãi cô không bắt máy". Qua đó cho thấy, sự quan tâm của GVCN đến HS vẫn còn hạn chế. Trên thực tế công tác giáo dục $\mathrm{HS}$, ngoài trách nhiệm, người $\mathrm{GVCN}$ cần phải quan tâm, tìm hiểu, giải đáp những vướng mắc trong học tập, cũng như quan hệ bạn bè trên lớp và các mối quan hệ khác..., với những yêu cầu trên, để công tác GVCNL phát huy được hiệu quả thì người GVCN phải nhận thức rõ vị trí, vai trò tầm quan trọng của mình trong CTCNL.

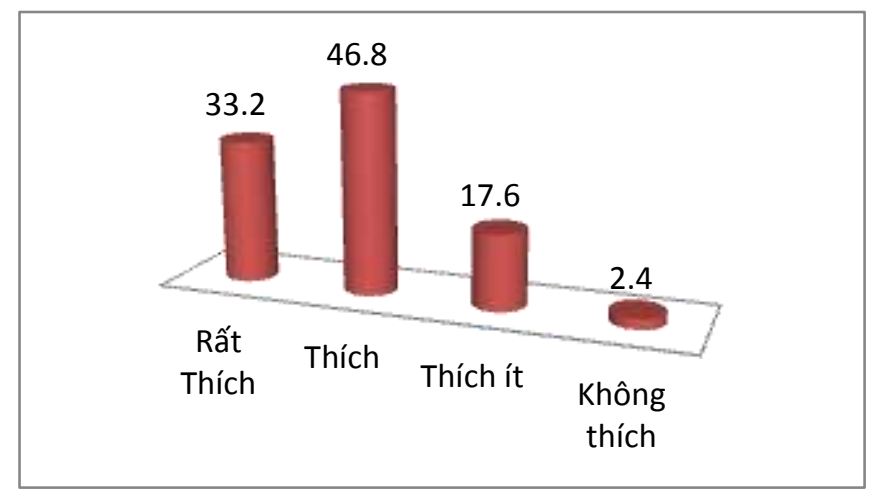

Biểu đồ 4. Sự hứng thú của HS trong tiết sinh hoạt cuối tuần lớp chủ nhiệm 
Giáo viên không chỉ là người cung cấp tri thức cho HS mà còn là người biết khơi nguồn, truyền cảm hứng cho $\mathrm{HS}$ trong học tập. Hơn thế nữa $\mathrm{GVCN}$ vừa là nhà quản lý, vừa là giáo dục một tập thể thu nhỏ (lớp học). Một trong những nhiệm vụ quan trọng của $\mathrm{GVCN}$ là tổ chức giờ sinh hoạt lớp, giờ sinh hoạt lớp phải làm thế nào để tạo nên sự hứng thú, từ đó luôn cuốn HS vào các hoạt động tích cực.

Kết quả biểu đồ 4 cho thấy có $33.2 \%$ ý kiến đánh giá rất thích, $46.8 \%$ ý kiến đánh giá thích, $17.6 \%$ ý kiến đánh giá thích ít, $2.4 \%$ ý kiến đánh giá không thích. Như vậy, hoạt động tổ chức giờ sinh hoạt lớp của GV các trường THCS khá hiệu quả $(80 \%)$ đã tạo sự hứng thú cho HS tham gia các hoạt động tích cực. Bên cạnh đó vẫn còn $17.6 \%$ thích ít và $2.4 \%$ không thích. Một trong những nhiệm vụ quan trọng của người GVCN đó là tổ chức giờ sinh hoạt lớp, sinh hoạt lớp là dạng hoạt động giáo dục tập thể, là một hình thức tổ chức tự quản cho HS và là một trong những biện pháp cơ bản góp phần xây dựng tập thể HS đoàn kết. Chính giờ sinh hoạt lớp, các em có thể bày tỏ, chia sẻ tâm tư, nguyện vọng, tự đánh giá nhận xét với nhau một cách thẳng thắn, tích cực và cũng qua giờ sinh hoạt lớp, các em được tham gia các hoạt động vui chơi mang tính giáo dục. Tuy nhiên thường HS không thích giờ sinh hoạt lớp vì nhiều nguyên nhân "Giờ sinh hoạt cô chỉ la mắng các em, rồi lại kiểm điểm, mời phu huynh, chán thật!" (HS trường THCS NVT), điều này cho thấy một số giờ sinh hoạt không đạt hiệu quả như mục tiêu đã đề ra, nhiều giáo viên chưa nắm rõ mục tiêu của giờ sinh hoạt lớp, không đầu tư đúng mức cho giờ sinh hoạt đó chính là một trong những nguyên nhân làm cho HS không thích giờ sinh hoạt. Để đổi mới căn bản toàn diện nền giáo dục, không thể không đổi mới CTCNL, trong đó thực hiện giờ sinh hoạt lớp là một khâu quan trọng cần phải đưa vào nội dung công tác bồi dưỡng CTCNL. Bảng 1 thể hiện thực trạng nội dung công tác chủ nhiệm.

Bảng 1. Thực trạng công tác chủ nhiệm lớp

\begin{tabular}{|c|c|c|c|c|c|c|c|}
\hline \multirow[b]{2}{*}{ Nội dung công tác } & \multicolumn{5}{|c|}{ Tỉ lệ đánh giá mức độ \% } & \multirow[b]{2}{*}{ ĐТВ } & \multirow[b]{2}{*}{$\begin{array}{l}\text { Thứ } \\
\text { bậc }\end{array}$} \\
\hline & & Tốt & Khá & TB & $\begin{array}{c}\text { Chưa } \\
\text { đạt }\end{array}$ & & \\
\hline \multirow{2}{*}{$\begin{array}{l}\text { 1. Tìm hiếu HS lớp chủ nhiệm: Tìm hiểu đặc điểm } \\
\text { lớp chủ nhiệm; hoàn cảnh và đặc điểm tâm lý HS; } \\
\text { các mối quan hệ của HS (gia đình, bạn bè, thầy, cô) }\end{array}$} & SL & 26 & 68 & 76 & 30 & \multirow{2}{*}{2.45} & \multirow{2}{*}{6} \\
\hline & $\%$ & 13 & 43 & 38 & 15 & & \\
\hline \multirow{2}{*}{$\begin{array}{l}\text { 2. Lập kế hoạch công tác chủ nhiệm: Kế hoạch cụ } \\
\text { thể, rõ ràng; xác định rõ mục tiêu giáo dục }\end{array}$} & SL & 98 & 59 & 43 & 0 & \multirow{2}{*}{3.28} & \multirow{2}{*}{4} \\
\hline & $\%$ & 49 & 29.5 & 21.5 & 0 & & \\
\hline \multirow{2}{*}{$\begin{array}{l}\text { 3. Chỉ đạo thực hiện nội dung GD toàn diện: Giáo } \\
\text { dục tư tưởng, phẩm chất đạo đức cho học sinh; tổ } \\
\text { chức các hoạt động học tập; hoạt động hướng } \\
\text { nghiệp; hoạt động văn hóa, nghệ thuật, TDTT }\end{array}$} & SL & 134 & 16 & 20 & 0 & \multirow[t]{2}{*}{3.57} & \multirow[t]{2}{*}{1} \\
\hline & $\%$ & 67 & 23 & 10 & 0 & & \\
\hline \multirow[t]{2}{*}{$\begin{array}{l}\text { 4. Xây dựng, quản lý tập thể HS lớp chủ nhiệm: Tồ } \\
\text { chức phân công bộ máy tự quản phù hợp; quan tâm } \\
\text { HS có hoàn cảnh đặc biệt, HS chưa ngoan }\end{array}$} & SL & 120 & 49 & 31 & 0 & \multirow[t]{2}{*}{3.45} & \multirow[t]{2}{*}{2} \\
\hline & $\%$ & 60 & 24.5 & 15.5 & 0 & & \\
\hline \multirow[t]{2}{*}{$\begin{array}{l}\text { 5. Phối hợp với các lực lượng GD khác: Phối hợp với } \\
\text { BGH và các lực lượng trong nhà trường; với gia đình } \\
\text { HS; với các lực lượng ngoài nhà trường. }\end{array}$} & SL & 38 & 112 & 40 & 0 & \multirow[t]{2}{*}{2.99} & \multirow[t]{2}{*}{5} \\
\hline & $\%$ & 19 & 61 & 20 & 0 & & \\
\hline \multirow{2}{*}{$\begin{array}{l}\text { 6. Tư vấn tâm lí HS: Tư vấn những vướng mắc khó } \\
\text { khăn trong học tập, quan hệ bạn bè, thầy cô; vấn đề } \\
\text { tâm, sinh lý lựa tuồi }\end{array}$} & SL & 8 & 65 & 104 & 23 & \multirow[t]{2}{*}{2.29} & \multirow[t]{2}{*}{7} \\
\hline & $\%$ & 4 & 32.5 & 52 & 11.5 & & \\
\hline \multirow{2}{*}{$\begin{array}{l}\text { 7. Đánh giá kết quả toàn diện của HS: Đánh giá hạnh } \\
\text { kiểm HS; tham gia đánh giá học lực HS; mức độ tiến bộ } \\
\text { của mỗi HS }\end{array}$} & SL & 101 & 63 & 36 & 0 & \multirow[t]{2}{*}{3.33} & \multirow[t]{2}{*}{3} \\
\hline & $\%$ & 50.5 & 31.5 & 18 & 0 & & \\
\hline
\end{tabular}


Bảng 1 cho thấy với 7 nội dung khảo sát ý kiến về thực hiện CTCN lớp của GV, các ý kiến đều đánh giá chỉ đạt mức độ trung bình và khá với tỉ lệ phần trăm khá cao. Điều này cho thấy, các nội dung CTCNL được đội ngũ GVCNL trên địa bàn thị xã Thuận An thực hiện khá tốt. Như vậy để thực hiện mục tiêu giáo dục thì việc thực hiện có hiệu quả CTCN sẽ góp phần nâng cao chất lượng các mặt hoạt động giáo dục, trên địa bàn toàn thị xã. Tuy nhiên vẫn còn 2 nội dung của $\mathrm{CTCN}$ liên quan đến việc tìm hiểu và tư vấn $\mathrm{HS}$ của $\mathrm{GV}$ chủ nhiệm được đánh giá ở mức trung bình và thứ bậc thấp nhất cụ thể:

Tìm hiểu HS lớp chủ nhiệm có $13 \%$ ý kiến đánh giá tốt, $43 \%$ ý kiến đánh giá khá, $38 \%$ ý kiến đánh giá trung bình, $15 \%$ ý kiến đánh giá chưa đạt, ĐTB là 2.45 , xếp thứ 6 . Điều này cho thấy công tác tìm hiểu HS lớp chủ nhiệm được thực hiện ở mức chưa cao vẫn còn $15 \%$ ý kiến đánh giá chưa đạt. Công tác tìm hiểu HS lớp chủ nhiệm là nhiệm vụ vô cùng quan trọng của người GVCNL, đặc biệt đối với tập thể lớp có HS cá biệt, thì nhiệm vụ này càng trở nên quan trọng hơn bao giờ hết.

Tư vấn tâm lí HS có $4 \%$ ý kiến đánh giá tốt, $32.5 \%$ ý kiến đánh giá khá, $52 \%$ ý kiến đánh giá trung bình, $11.5 \%$ ý kiến đánh giá chưa đạt, ĐTB: 2.29 , xếp thứ 7 . GVCN không chỉ là người cố vấn định hướng triển khai, cho các hoạt động tập thể lớp chủ nhiệm mà còn là "cầu nối" lắng nghe và tìm hiểu, giải mã những bức xúc của HS, hỗ trợ cho các em những vướng mắc về tâm sinh lý, về học tập, về cuộc sống... Từ đó tư vấn, kịp thời phát hiện những lo âu, chấn chỉnh những hành vi sai lệch, động viên khuyến khích một cách khách quan những hoạt động nhiều mặt của HS theo hướng tích cực. Thực tế cho thấy hoạt động tư vấn tâm lí HS của các trường THCS trên địa bàn thị xã Thuận An có triển khai thực hiện nhưng chưa theo kịp sự phát triển tâm sinh lý và nhu cầu tư vấn, tham vấn ngày càng đa dạng của HS.

\section{KẾT LUẬN VÀ KIẾN NGH!}

\subsection{Kết luận}

Từ kết quả khảo sát trên cho thấy các hoạt động CNL đã thực hiện đúng mục tiêu, đội ngũ GVCN nhiệt tình, triển khai đúng các nội dung CNL theo kế hoạch của nhà trường, của phòng GDĐT thị xã Thuận An. Tuy nhiên, trong bối cảnh đổi mới giáo dục - đào tạo hiện nay, những kết quả nói trên chưa đủ để đáp ứng yêu cầu, nhiệm vụ mới. Những tồn tại về nhận thức, về kế hoạch, về triển khai nội dung và phương pháp,... tổ chức hoạt động $\mathrm{CNL}$ cần phải được rút kinh nghiệm, khắc phục và điều quan trọng là cũng phải khắc phục những bất cập trong hoạt động quản lý CTCN của HT các trường THCS trên địa bàn thị xã Thuận An.

\subsection{Kiến nghị}

Để công tác CNL đạt kết quả cao hơn, đáp ứng tốt hơn yêu cầu, nhiệm vụ mới, lãnh đạo phòng và hiệu trưởng các trường THCS thị xã Thuận An cần: Nâng cao nhận thức, trình độ, năng lực thực hiện công tác chủ nhiệm lớp trong bối cảnh đổi mới giáo dục hiện nay. Làm cho đội ngũ GVCN nắm được những cơ sở khoa học của CTCNL, những kỹ năng cơ bản của người làm công tác GD học sinh, không chủ quan, duy ý chí trong việc hướng dẫn HS. Vì vậy, phải không ngừng nâng cao trình độ, năng lực, ý thức trách nhiệm về CTCNL thông qua các buổi tập huấn, bồi dưỡng chuyên đề, hội thi GVCNG...

Cải tiến công tác xây dựng kế hoạch chủ nhiệm: Kế hoạch CTCN được xây dựng theo khung thời gian; kế hoạch năm học, kế hoạch học kỳ, kế hoạch tháng, kế hoạch tuần, mỗi giai đoạn có những nội dung khác nhau được thể hiện rõ ràng, cụ thể và các nội dung phải bám sát vào văn bản chỉ đạo của các ban ngành liên quan. Đồng thời, kế hoạch phải xác định mục tiêu cần đạt, phù hợp với điều kiện thực tế nhà trường về nội dung và cách thức thực hiện, có tính khả thi, cụ thể hóa thời gian thực hiện các hoạt động. Kế hoạch CTCN phải đảm bảo tính thống nhất cao giữa các thành viên trong nhà trường.

Cùng với việc tập huấn, bồi dưỡng đội ngũ GVCN, cần xây dựng đội ngũ kế cận và phân công GVCN giỏi kèm cặp giúp đỡ cho những GV trẻ, còn ít kinh nghiệm để có thể bổ sung, thay thế, điều chỉnh kịp thời nhân lực công tác CNL.

Tăng cường tìm hiểu tâm lý học sinh, hoàn cảnh gia đình các em bằng nhiều hình thức khác nhau như kết bạn với học sinh trên facebook, trò chuyện trực tiếp ngoài giờ, qua bạn bè, người thân của học $\sinh \ldots$

Thành lập phòng tham vấn tâm lý ở trường THCS để giúp học sinh tháo gỡ những khó khăn trong giao tiếp, trong học tập, đặc biệt là tâm sinh lý giới tính nhằm giúp các em hiểu rõ bản thân và người khác để cùng hợp tác trong học tập và tham gia hoạt động chung của trường, lớp. 


\section{TÀI LIỆU THAM KHẢO}

[1] Bộ GD-ĐT (2011), Điều lệ trường Trung học cơ sở, Trung học phổ thông và trường Phổ thông có nhiều cấp học, ban hành kèm theo Thông tư 12/2011/TT-BGDĐT ngày 28/3/2011 của Bộ trưởng Bộ GD-ĐT.

[2] Ban Chấp hành Trung ương (2013), Nghị quyết số 29-NQ/TW ngày 4/11/2013 về đổi mới căn bản, toàn diện giáo dục và đào tạo, đáp ứng yêu cầu công nghiệp hóa, hiện đại hóa trong điều kiện kinh tế thị trường định hướng xã hội chủ nghĩa và hội nhập quốc tế.

[3] Bộ GD-ĐT (2014), Thông tư 04/2014/TT-BGD ĐT của Bộ GD-ĐT ngày 28/02/2014 về ban hành Quy định QL hoạt động giáo dục kĩ năng sống và hoạt động giáo dục ngoài giờ chính khóa.

[4] Bộ giáo dục và Đào tạo (2015) văn bản số 463/ BGDĐT-GDTX về việc triển khai thực hiện giáo dục kỹ năng sống tại các cơ sở GDMN, GDPT và GDTX.

Ngày nhận bài:16/10/2017

Ngày chấp nhận đăng:12/02/2018 